\title{
Comment on Singh et al.: Fractures of capitellum: a review of 14 cases treated by open reduction and internal fixation with Herbert screws
}

\author{
Anil Agarwal
}

Received: 8 December 2009 / Accepted: 23 December 2009 /Published online: 2 February 2010

(C) Springer-Verlag 2010

We read with deep interest the article by Singh et al. [1]. We thank the authors for sharing with us such experience with these rare injuries.

Since the capitellum injury is an uncommon fracture, the described technique left certain queries unanswered for the less experienced user. Do the authors routinely recommend $\mathrm{CT}$ in all capitellum fractures as assessment of fracture comminution by plain radiographs is particularly deceptive in this region [2]? Again, how long did the fractures take to unite and how was the union assessed radiologically? Singh et al. recommend very early mobilisation (e.g. illustrative case 2) of elbow joint even in bone grafted cases, which is not a common clinical practice, unless the graft itself is stabilised. Moreover, the fracture fragments are often osteoporotic in old fractures, precluding stable fixation, and the risk of implant cutting through remains high with such early mobilisation. Singh et al. also managed three capitel- lum fractures which were more than six months old. An older epiphyseal fracture usually presents with hypertrophy of articular cartilage, rounding of margins and sometimes it is practically impossible to make out the proximal fractured surface of the fragment. Despite a meticulous surgical technique, restoration of joint congruity is difficult. Did Singh et al. face such difficulties in their series?

\section{References}

1. Singh AP, Singh AP, Vaishya R, Jain A, Gulati D (2009) Fractures of capitellum: a review of 14 cases treated by open reduction and internal fixation with Herbert screws. Int Orthop. doi:10.1007/ s00264-009-0896-9

2. Mahirogullari M, Kiral A, Solakoglu C, Pehlivan O, Akmaz I, Rodop O (2006) Treatment of fractures of the humeral capitellum using Herbert screws. J Hand Surg Br 31:320-325

\footnotetext{
A. Agarwal

Department of Paediatric Orthopaedics, CNBC,

Geeta Colony,

Delhi, India

A. Agarwal $(\bowtie)$

4/103, East End Apartments, Mayur Vihar Ph-I Ext,

Delhi 110096, India

e-mail: rachna_anila@yahoo.co.in
} 